\title{
Clinical course and risk factors of hepatitis C virus related liver disease in the general population: report from the Dionysos study
}

S Bellentani, G Pozzato, G Saccoccio, M Crovatto, L S Crocè, L Mazzoran, F Masutti, G Cristianini, C Tiribelli

\begin{abstract}
Background-The severity, clinical course, and risk of hepatitis $C$ virus (HCV) related chronic liver disease are still rather poorly defined.

Aims-To investigate the prevalence, risk factors, and severity of HCV related liver disease in the general population, and investigate whether infection with a specific genotype is associated with an increased risk of cirrhosis or hepatocellular carcinoma.
\end{abstract}

Methods-HCV RNA determination by polymerase chain reaction (PCR) and HCV genotyping were performed in all anti-HCV positive subjects belonging to the Dionysos study (6917 subjects). Diagnosis of cirrhosis and hepatocellular carcinoma was established by liver biopsy in all cases. All the data were analysed by univariate and multivariate statistics in all the cohort. To investigate the natural history of HCV infection, anti-HCV positive subjects were followed up every six months for three years with liver function tests and ultrasonograms.

Results-The overall prevalence of $\mathrm{HCV}$ RNA positivity was $2.3 \%$. Positivity increased progressively with age, and was higher in women (ratio of men to women = $0.7)$. Genotypes $1 b$ and $2 a$ were the most frequent ( 42 and $24 \%$ of HCV RNA positive patients), with a prevalence of 1 and $0.6 \%$ respectively. Intravenous drug use, blood transfusions received before 1990, history of previous hepatitis among the cohabiting, and history of animal (mainly dogs) bites were significantly $(p<0.05)$ associated with $\mathrm{HCV}$ infection, independently of age and sex. Multivariate analysis showed that, independently of age, sex, and alcohol intake, genotype $1 \mathrm{~b}$ infection, with or without coinfection with other genotypes, is the major risk factor associated with the presence of cirrhosis and/or hepatocellular carcinoma. During the three years of follow up, $57(35 \%)$ of the HCV RNA positive subjects had consistently normal alanine aminotransferase and $\gamma$-glutamyltransferase values. Two of the $22 \mathrm{HCV}$ RNA positive cirrhotic patients, all drinking more than $90 \mathrm{~g}$ of alcohol a day, developed hepatocellular carcinoma (incidence rate $=3.0 \%$ per year).
Conclusions-In the general population of Northern Italy, HCV infection is widespread, but only less than $50 \%$ of the antiHCV positive subjects, particularly those infected with genotype $1 \mathrm{~b}$, are associated with a more severe liver disease. Alcohol consumption greater that $30 \mathrm{~g}$ a day significantly aggravates the natural course of the disease.

(Gut 1999;44:874-880)

Keywords: hepatitis C virus genotypes; Dionysos; liver disease; cirrhosis

Several genotypes of the hepatitis C virus (HCV) show a great variability in genomic sequence. ${ }^{1-5} \mathrm{~A}$ controversial issue is whether HCV genotype $1 b$ infection carries a worse prognosis for chronic liver disease ${ }^{6-15}$ and whether it is more resistant to interferon treatment than other genotypes. ${ }^{16}{ }^{17}$ Most published data are based on selected series of patients referred to liver centres, and data on the prevalence of different HCV genotypes and the severity of associated chronic liver disease in the general population are few. ${ }^{6}$ Seven years ago, our group started a cohort study, named Dionysos, ${ }^{18}{ }^{19}$ in order to document the true prevalence of chronic liver disease in a geographically defined population in Northern Italy.

To address controversial issues about the prevalence of HCV infection and its genotype distribution, pattern of transmission, role of alcohol consumption, and the severity of associated chronic liver disease in the general population, we determined the prevalence of different $\mathrm{HCV}$ genotypes and the risk factors for $\mathrm{HCV}$ transmission. In all the subjects enrolled in the continuing Dionysos cohort study, the presence of HCV related cirrhosis or hepatocellular carcinoma (HCC) was also evaluated.

\section{Materials and methods}

ENROLMENT OF PATIENTS AND COMPLIANCE

The details of the overall design of the Dionysos study have already been published. ${ }^{18-20}$ Briefly, all the 10151 inhabitants between 12 and 65 years of age of two North-

Abbreviations used in this paper: $\mathrm{HCV}$, hepatitis $\mathrm{C}$ virus; HCC, hepatocellular carcinoma; PCR, polymerase chain reaction; ALT, alanine aminotransferase; AST, aspartate aminotransferase; GGT, $\gamma$-glutamyltransferase; ELISA, enzyme linked immunosorbent assay; OR, odds ratio. 
ern Italian towns received a written invitation to participate in the study. Of these, 6917 were enrolled during the two years of the study. This number represents $69 \%$ of the eligible population - that is, a fraction adequate to validate this type of study. ${ }^{20}$

INITIAL EVALUATION

As described more completely elsewhere,${ }^{18}$ the following were performed.

(1) A medical history was taken including family history of hepatitis in cohabiting people, presence of gallstone disease, history of past surgical operations, blood transfusions before 1990, drug abuse, dental procedures, dog or other domestic animal bites, homosexuality, acupuncture. The use of drugs was also registered.

(2) A semiquantitative colour illustrated food questionnaire $^{21-23}$ was administered which included detailed questions on the use of alcoholic beverages (wine, beer, alcoholic aperitifs, hard liquor) and the dose, duration of use and the time of drinking. Daily alcohol intake (in g) was computed by multiplying the frequency of consumption of each unit of beverage by the alcohol content of the specified portions, according to standard procedures. ${ }^{24} 25$

(3) A detailed physical examination was carried out aimed at detecting physical signs related to chronic liver disease.

(4) A blood sample was taken for determination of serum alanine aminotransferase (ALT), aspartate aminotransferase (AST), $\gamma$-glutamyltransferase (GGT), mean cell volume, platelet, erythrocyte and leucocyte count, hepatitis B surface antigen, hepatitis B surface antibody (Abbott Diagnostic Kits, North Chicago, Illinois, USA) and hepatitis C virus antibody (anti-HCV) (enzyme linked immunosorbent assay (ELISA), third generation; Ortho Diagnostic Systems, Raritan, New Jersey, USA).

The diagnosis of cirrhosis was clinically suspected when at least two of the following features were present: (a) spider nevi, scleral icterus, palmar erythema, ascites, flapping tremor, hepatic or splenic enlargement; $(b)$ platelet count less than $140000 / \mathrm{mm}^{3}$; (c) portal vein diameter greater than $12 \mathrm{~mm}$ or irregular margins of the liver parenchyma at ultrasonography.

VIROLOGICAL STUDIES

In all patients the presence of anti-HCV antibodies was assayed by a second generation (four antigen) immunoenzymatic screening test (Ortho-HCV; Ortho Diagnostic Systems). This assay detects specific reactivity to four $\mathrm{HCV}$ antigens, including three non-structural (C100-3, 5-1-1, C-33c) and one structural (C22). In positive samples the presence of anti$\mathrm{HCV}$ antibodies was confirmed by a third generation immunoenzymatic test (Ortho Diagnostic Systems) and by a confirmatory test (RIBA; Chiron Corp, Emeryville, California, USA). Sera showing two or more positive bands were considered "positive", whereas those with only one band (usually C22) were defined as "indeterminate" and those without $\mathrm{HCV}$ antigen bands as "negative".

HCV RNA DETECTION

The presence of HCV RNA in the serum was assessed by polymerase chain reaction (PCR) amplification of the 5' untranslated region of $\mathrm{HCV}$, which is considered to be the most conserved region of the virus. The test was performed in all subjects testing positive for the presence of anti-HCV antibodies (screening test). The amplification was performed in two steps, so called nested PCR.

After extraction, cDNA synthesis was performed with an antisense external primer according to standard methods. ${ }^{26}$

HCV RNA detection was performed in the serum samples collected at presentation. If viral RNA was found, no additional determination was carried out; if HCV RNA was undetectable, the test was repeated on fresh serum samples collected during follow up.

\section{HCV GENOTYPING}

The HCV genotype was determined by PCR amplification of the core region as described by Okamoto, ${ }^{26}{ }^{27}$ and classified according to the international Simmonds nomenclature. ${ }^{28}$ Each HCV type was characterised by a different nucleotide length: 49 for type 1a, 144 for type $1 \mathrm{~b}, 174$ for type $2 \mathrm{a}$, and 123 for type $2 \mathrm{~b}$. When a double infection was suspected because of the presence of several bands, a second PCR was repeated separately with each of four typespecific antisense primers. Primers were also added to enable detection of type $3 \mathrm{a} \mathrm{HCV}{ }^{27}{ }^{29}$

FOLLOW UP OF ANTI-HCV POSITIVE SUBJECTS Each participant initially positive for anti-HCV atibody (and confirmed to be positive by third generation ELISA and the RIBA test) and each subject for whom the diagnosis of cirrhosis was suspected clinically (see above) underwent the following additional procedures every six months for at least three years: (a) repetition of baseline blood tests plus, as well as serum alkaline phosphatase, bilirubin, albumin, $\gamma$-globulin, prothrombin time, and $\alpha$-fetoprotein, blood assay of glucose, cholesterol, and triglycerides; (b) ultrasonography of the liver, biliary system, pancreas, and spleen with the measurement of portal vein and retropancreatic splenic vein diameters (all sonograms were performed by one operator).

All of the $162 \mathrm{HCV}$ RNA positive subjects with either ALT more than 1.5 times the upper limit of normal in at least two after one month interval check $(\mathrm{n}=55)$ or with clinically suspected cirrhosis according to the criteria reported above $(n=25)$ were asked to undergo percutaneous liver biopsy. Of these, 79 met these criteria, and 77 had biopsies. Two patients with ALT more than 1.5 times the upper limit of normal, but without clinically suspected cirrhosis, declined to have a biopsy.

STATISTICAL ANALYSIS

Statistical analysis was performed with an SPSS/PC statistical package (SPSS Inc, Chi- 
Table 1 Anti-hepatitis $C$ virus (HCV) positivity and HCV genotype distribution according to age, as well as overall prevalence (\%) of the different HCV genotypes in the general population $(n=6917)$ and the age distribution in the population of reference (total Dionysos cohort)

\begin{tabular}{|c|c|c|c|c|c|c|c|c|}
\hline HCV genotype & 12-25 years & $26-35$ years & $36-45$ years & $46-55$ years & 56-65 years & Total $\leqslant 45$ years & Total $>45$ years & Overall \\
\hline Total Dionysos population & $1464(21.2)$ & $1347(19.5)$ & $1354(19.6)$ & $1368(19.8)$ & $1384(20.0)$ & $4165(60.2)$ & $2752(39.8)$ & 6917 \\
\hline Anti-HCV positive & $9(4.0)$ & $20(8.8)$ & $26(11.5)$ & $56(24.8)$ & $115(50.9)$ & $55(24.3)$ & $171(75.7)^{\star}$ & $226(3.2)$ \\
\hline HCV-RNA positive & $5(3.1)$ & $14(8.6)$ & $12(7.4)$ & $43(26.5)$ & $88(54.3)$ & $31(19.1)$ & $131(80.9)^{\star}$ & $162(2.3)$ \\
\hline Type $1 \mathrm{a}$ & $0(0.0)$ & $2(28.6)$ & $1(14.3)$ & $2(28.6)$ & $2(28.6)$ & $3(42.9)$ & $4(57.1)$ & $7(0.1)$ \\
\hline Type $1 \mathrm{~b}$ & $1(1.5)$ & $5(7.4)$ & $5(7.4)$ & $23(33.8)$ & $34(50.0)$ & $11(16.2)$ & $57(83.8)^{\star}$ & $68(1.0)$ \\
\hline Type $2 \mathrm{a}$ & $1(2.6)$ & $1(2.6)$ & $4(10.3)$ & $12(30.8)$ & $21(53.8)$ & $6(15.4)$ & $33(84.6)^{\star}$ & $39(0.6)$ \\
\hline Type $2 b$ & $0(0.0)$ & $0(0.0)$ & $0(0.0)$ & $0(0.0)$ & $1(100)$ & $0(0.0)$ & $1(100)$ & $1(0.01)$ \\
\hline Type $2 \mathrm{c}$ & $0(0.0)$ & $0(0.0)$ & $0(0.0)$ & $2(50.0)$ & $2(50.0)$ & $0(0.0)$ & $4(100)$ & $4(0.06)$ \\
\hline Type $3 \mathrm{a}$ & $0(0.0)$ & $2(66.7)$ & $0(0.0)$ & $0(0.0)$ & $1(33.3)$ & $2(66.7)$ & $1(33.3)$ & $3(0.04)$ \\
\hline $\mathrm{Co} 2$ & $0(0.0)$ & $0(0.0)$ & $0(0.0)$ & $0(0.0)$ & $3(100)$ & $0(0.0)$ & $3(100)$ & $3(0.04)$ \\
\hline $\mathrm{Co} 3$ & $0(0.0)$ & $3(27.3)$ & $1(9.1)$ & $1(9.1)$ & $6(54.5)$ & $4(36.4)$ & $7(63.6)$ & $11(0.16)$ \\
\hline UT & $3(11.5)$ & $1(3.8)$ & $1(3.8)$ & $3(11.5)$ & $18(69.2) \dagger$ & $5(19.2)$ & $21(80.8)^{\star}$ & $26(0.38)$ \\
\hline
\end{tabular}

Values in parentheses are percentages.

Co2, coinfections by two HCV genotypes (two patients infected by genotypes $1 \mathrm{~b}$ and $2 \mathrm{~b}$ and one by genotype $1 \mathrm{~b}$ and $2 \mathrm{a}$ ); Co3, coinfections by three HCV genotypes (five of the 11 patients infected by genotypes $1 \mathrm{a}, 1 \mathrm{~b}$ and $2 \mathrm{a}$ and the other six by genotypes $1 \mathrm{~b}, 2 \mathrm{a}$ and $2 \mathrm{~b}$ ); UT, untypable genotypes.

${ }^{\star} \mathrm{p}<0.002 v$ total $\leqslant 45 ; \mathrm{tp}<0.01 v$ all the other age ranges.

cago, Illinois, USA). All p values reported are two tailed. Statistical comparisons between means were made by one way analysis of variance, and, when the variances were not homogeneous, by the Kruskal-Wallis one way analysis of variance. ${ }^{30}$

At the univariate analysis within the general Dionysos population, the following covariates were considered as possibly related to $\mathrm{HCV}$ infection: age, sex, daily alcohol intake, history of hepatitis among the cohabiting people, past surgical procedure, past dental procedures, intravenous drug use, acupuncture, blood transfusion before 1990, animal bites, and homosexuality. The association between the presence of cirrhosis/HCC and different HCV genotypes, after correction for age, sex, and daily alcohol intake, was also considered both within the general Dionysos population and the $\mathrm{HCV}$ infected population.

The factors selected were judged eligible to enter the multivariate model on the basis of the following tests ${ }^{31}$ : (a) significance test on Pearson correlation coefficient under the null hypothesis of $\rho=0$; (b) two-sample $t$ test (analysis of variance) on mean values with correction for unequal variances when detected; (c) likelihood ratio $\chi^{2}$ statistic for testing the significance of explanatory variables, one at a time, from a linear logistic regression model. A significance level lower than 0.05 was considered the criterion for entry into the initial multivariate model.

The multivariate analysis was carried out using a linear logistic regression model, ${ }^{32}$ with a stepwise variable selection procedure (level for entry $=0.1$, level for stay $=0.5$ ). The models explain either the probability of $\mathrm{HCV}$ infection according to the different exposure risk factors or the probability of having cirrhosis/HCC according to the different $\mathrm{HCV}$ genotypes among both the total Dionysos cohort and the $\mathrm{HCV}$ infected population followed up for three years. As coinfection with two or three $\mathrm{HCV}$ genotypes was always associated with genotype $1 \mathrm{~b}$, results for patients infected with multiple genotypes were pooled with those for patients infected with HCV genotype $1 \mathrm{~b}$ in the multivariate analysis. Independently of the used selection criteria, age and sex factors were always considered in the multivariate analysis in order to improve model fitting. During analysis for the association between the presence of cirrhosis/HCC and the presence of different HCV genotypes, daily alcohol intake was also always forced into the model. Odds ratios (OR) and 95\% confidence intervals were also calculated. ${ }^{32}$

\section{Results}

PREVALENCE OF HCV GENOTYPE INFECTION ACCORDING TO AGE AND SEX

The anti-HCV screening test was positive in 226 cases $(3.2 \%)$. RIBA gave indeterminate results in 20 cases $(9 \%)$, negative in $27(12 \%)$, and positive in the remaining 179 cases $(79 \%)$. Viral RNA was found in 154 of 179 RIBA positive cases $(86 \%)$ and in six RIBA "indeterminate" cases $(30 \%)$. Interestingly, two of the 27 RIBA negative cases $(7 \%)$ were found to be HCV RNA positive. HCV RNA was detected in the serum in 162 cases $(2.3 \%)$. The prevalence $(\mathrm{P})$ of anti-HCV and HCV RNA positivity increased progressively with age. As shown in table 1 , the prevalence was low in the age range $12-25$ years, and more than two thirds of the positive subjects were older than 45.

Of the $162 \mathrm{HCV}$ RNA positive subjects (table 1 and fig 1 ), seven (4.3\%) were type $1 \mathrm{a}$ $(\mathrm{P}=0.1 \%), 68(42 \%)$ type $1 \mathrm{~b}(\mathrm{P}=1.0 \%), 39$ (24\%) type $2 \mathrm{a}(\mathrm{P}=0.6 \%)$, one $(0.6 \%)$ type $2 \mathrm{~b}$ $(\mathrm{P}=0.01 \%)$, four $(2.5 \%)$ type $2 \mathrm{c}(\mathrm{P}=0.06 \%)$, three $(1.8 \%)$ type $3 \mathrm{a}(\mathrm{P}=0.04 \%)$, three $(1.8 \%)$ were coinfected with two genotypes ( $\mathrm{P}$ $=0.04 \%)$, and $11(6.8 \%)$ with three genotypes $(\mathrm{P}=0.16 \%)$. Coinfection was always associated with the presence of genotype 1b. In 26 cases the core amplification was positive, but multiple or unexpected bands were found in the agarose and polyacrylamide gels; as PCR amplification was performed three times with the same results, these cases were considered as "untypable" ( $\mathrm{P}=0.38 \%)$.

The HCV genotype varied according to age (table 1). The percentage of subjects infected with all the HCV genotypes, except for genotype 3a, was significantly higher over 45 years $(p<0.002)$ than under. The percentage of "untypable" genotype was significantly $(p<0.05)$ higher in the 56-65 age range than in the others (table 1). The mean age of patients infected by the various HCV genotypes does not differ significantly. The prevalence of both 




Figure 1 Distribution of different hepatitis $C$ virus (HCV) genotypes in the HCV RNA positive subjects of the Dionysos cohort $(n=162)$.

anti-HCV and HCV RNA positivity was greater in women than men (ratio of men to women $=0.7)$ in all the age ranges considered.

RISK FACTORS FOR HCV INFECTION IN THE DIONYSOS COHORT

Tables 2 and 3 give the risk factors for exposure to $\mathrm{HCV}$ that were significantly $(\mathrm{p}<0.05)$ associated with positivity for HCV RNA and for different $\mathrm{HCV}$ genotypes both in the univariate and multivariate analysis. The univariate analysis (table 2) identified the presence of chronic hepatitis among the cohabiting, both surgical and dental procedures, intravenous drug use, blood transfusions before 1990, and animal (mainly dog) bites as possibly related risk factors for the presence of $\mathrm{HCV}$ infection. When these factors were entered into the logistic multiple regression analysis (table 3), after correction for sex and age, only history of intravenous drug use, blood transfusions, previous hepatitis among the cohabiting, and animal bites were significantly $(p<0.05)$ associated with the presence of $\mathrm{HCV}$ infection.

RISK FACTORS FOR CIRRHOSIS/HCC IN THE DIONYSOS COHORT

The diagnosis of liver cirrhosis and/or HCC was confirmed by liver biopsy in all 78 cases in which the diagnosis was suspected clinically. As reported elsewhere, ${ }^{18}{ }^{19}$ the main causes of cirrhosis/HCC were HCV and alcohol abuse. Of the $162 \mathrm{HCV}$ RNA positive subjects, 20 $(12 \%)$ had cirrhosis and five $(3 \%)$ had HCC (four with cirrhosis as well). Diagnosis of cirrhosis was made at the initial evaluation. Fourteen of the 20 patients with cirrhosis $(70 \%)$ were infected with genotype $1 \mathrm{~b}$, three $(15 \%)$ with genotype $2 \mathrm{a}$, and the remaining three with genotype 1a, "untypable" genotype, and multiple genotypes (types $1 \mathrm{~b}, 2 \mathrm{a}$, and $2 \mathrm{~b}$ ). Two of the five patients with HCC, infected with genotype $1 \mathrm{~b}$, had that diagnosis made at the initial evaluation, while the other three (one without cirrhosis, infected with genotype $1 \mathrm{~b}$ and $2 \mathrm{a}$, the other two with cirrhosis, infected with an untypable genotype) developed HCC during the three years of follow up, with an incidence rate of two per 22 patients with $\mathrm{HCV}$ induced cirrhosis per three years, or 3\% per year. All five patients with HCC were alcohol abusers (mean (SD) daily alcohol intake was 122 (46) g; p<0.01 $v$ other patients with cirrhosis).
Of the remaining $52 \mathrm{HCV}$ RNA positive patients who underwent liver biopsy during the three years of follow up, 18 had minimal inflammation (11\%) and $34(21 \%)$ had chronic active hepatitis.

Fifty six HCV RNA positive patients (34\%) showed no abnormality of ALT, AST, or GGT, and $29(18 \%)$ had only a slight increase in either ALT or GGT.

Finally, of the 64 subjects positive for anti-HCV but negative for HCV RNA, 53 $(83 \%)$ showed no clinical, biochemical, or ultrasonographic alterations during the three years follow up. In the remaining 10 cases $(15.5 \%)$ a transient mild alteration in either GGT or ALT occurred. Of these 10 patients, one was obese, two had gallstones, and seven were alcohol abusers ( $60 \mathrm{~g}$ ethanol a day). Only one of these HCV RNA negative patients met the criteria for biopsy. He was found to have cirrhosis, but he was an alcohol abuser $(>120$ $\mathrm{g}$ ethanol a day).

In order to discriminate which is the most important factor correlated with the presence of cirrhosis and/or HCC between different HCV genotypes, age, sex, and daily alcohol intake in the Dionysos cohort, we performed a multiple regression logistic analysis. As reported in table 4, after correction for age, sex, and daily alcohol intake, the odds for a patient infected by both HCV genotype $1 \mathrm{~b}$ and multiple genotypes of having cirrhosis and/or HCC was 31 times higher (range 16-59) than for those patients not infected by HCV $(p<0.0001)$. The risk for a subject infected by all the other HCV genotypes of having cirrhosis and/or HCC was lower $(\mathrm{OR}=11.2$, range 4.4-28.6, $\mathrm{p}<0.0001$ ) but still highly significant compared with HCV RNA negative subjects.

When the multivariate analysis was performed considering only the HCV RNA positive population - that is, 162 subjectsafter correction for sex, age, and daily alcohol intake, the only HCV genotype significantly associated $(p=0.002)$ with the risk of having cirrhosis and/or HCC was genotype $1 \mathrm{~b}$, either alone or combined with other genotypes $(\mathrm{OR}=$ 4.0, range 1.6-9.8).

Similarly, the prevalence of cirrhosis and/or HCC in HCV RNA positive patients was significantly higher $(p<0.01)$ in patients infected by genotype 1 than in patients infected by all the other genotypes. In detail, $72 \%$ (18/ 25) of the liver cirrhosis with or without HCC was associated with genotype $1 \mathrm{~b}$. Conversely, only $25 \%$ of patients infected with genotype $1 \mathrm{~b}$ showed consistently normal levels of ALT or GGT during the three years of follow up.

Finally, by taking $30 \mathrm{~g}$ daily alcohol intake as the risk threshold for alcohol induced liver damage, as we previously showed in the same Dionysos cohort (21), 36 of the HCV RNA positive subjects $(22 \%)$ could be considered as drinkers at risk, while the remaining 126 were not. Thirteen of the $126 \mathrm{HCV}$ RNA positive subjects not at risk $(10 \%)$ had cirrhosis or HCC, while 12 of the 37 drinkers at risk (32\%) had cirrhosis $(\mathrm{p}<0.05)$. The risk of developing cirrhosis for HCV RNA positive drinkers was three times higher than that for drinkers not at 
Table 2 Univariate analysis of the potential risk factors for exposure to hepatitis $C$ virus (HCV) infection in the Dionysos cohort ( $n=6917$ subjects)

\begin{tabular}{llll}
\hline Risk factors & $\begin{array}{l}\text { Anti-HCV negative } \\
(n=6691)\end{array}$ & $\begin{array}{l}\text { Anti-HCV positive } \\
(n=226)\end{array}$ & $\begin{array}{l}\text { Pearson correlation } \\
\text { coefficient } p \text { value }\end{array}$ \\
\hline $\begin{array}{l}\text { Male sex } \\
\text { Alcohol intake }(>30 \mathrm{~g} / \text { day) }\end{array}$ & $3158(47)$ & $95(42)$ & 0.2524 \\
$\begin{array}{l}\text { Hepatitis among the } \\
\quad \text { cohabiting }\end{array}$ & $1449(22)$ & $52(23)$ & 0.0704 \\
$\begin{array}{l}\text { Surgical procedure } \\
\text { Dental procedures }\end{array}$ & $4878(73)$ & $60(27)$ & 0.0001 \\
Intravenous drug use & $3794(57)$ & $183(81)$ & 0.0056 \\
Acupuncture & $22(0.3)$ & $151(67)$ & 0.0295 \\
Blood transfusion & $355(5)$ & $18(8)$ & 0.0001 \\
Animal bites & $401(6)$ & $35(15)$ & 0.1395 \\
Homosexuality & $743(11)$ & $36(16)$ & 0.0001 \\
& $7(0.1)$ & $0(0)$ & 0.0391 \\
\hline
\end{tabular}

Values in parentheses are percentages.

Table 3 Multivariate analysis of the potential risk factors for exposure to hepatitis $C$ virus (HCV) infection in the Dionysos cohort ( $n=6917$ subjects). Analysis of maximum likelihood estimates

\begin{tabular}{llll}
\hline Risk factors & $\chi^{2}(p$ value $)$ & Odds ratio & $95 \% C I$ \\
\hline Sex (forced) & 0.2568 & 0.82 & $0.6-1.1$ \\
Age (forced) & 0.0001 & 1.1 & $1.0-1.1$ \\
Hepatitis among the cohabiting & 0.0003 & 2.0 & $1.4-2.8$ \\
Intravenous drug use & 0.0001 & 18.4 & $5.3-64.0$ \\
Animal bites & 0.0444 & 1.6 & $1.0-2.5$ \\
Blood transfusion & 0.0006 & 2.2 & $1.4-3.4$ \\
\hline
\end{tabular}

CI, confidence interval.

Table 4 Multivariate analysis of the risk factors for the presence of cirrhosis and/or hepatocellular carcinoma in the Dionysos cohort $(n=6917$ subjects $)$. Analysis of maximum likelihood estimates

\begin{tabular}{llll}
\hline Risk factors & $\chi^{2}$ (p value) & Odds ratio & $95 \%$ CI \\
\hline Sex (forced) & 0.06 & 1.7 & $1.0-3.0$ \\
Age (forced) & 0.002 & 1.0 & $1.0-1.1$ \\
Alcohol intake (g/day) (forced) & 0.0001 & 1.0 & $1.0-1.1$ \\
HCV genotype 1b (including multiple & & & $16.2-58.9$ \\
$\quad$ genotypes) & 0.0001 & 30.9 & $1.4-28.6$ \\
HCV genotypes other than 1b & 0.0001 & 11.2 & \\
\hline
\end{tabular}

CI, confidence interval.

risk $(95 \%$ confidence interval $=1.2-7.4$, $\mathrm{p}<0.01)$. Two of the $12 \mathrm{HCV}$ RNA positive cirrhotic patients who drank more than $30 \mathrm{~g}$ alcohol a day $(17 \%)$ were younger than 45 compared with only one of 13 cirrhotic non-drinkers $(7.7 \%, \mathrm{p}<0.05)$.

\section{Discussion}

Over the last few years, several studies have reported on the relation between different HCV genotype infections, and the increased risk of developing either cirrhosis or HCC. ${ }^{811}{ }^{14-16}$ However, most of these clinical studies are limited by a number of confounding factors, by fragmentary sampling, or by other risk factors such as alcohol intake. The Dionysos study avoids many of these problems because the cohort of subjects studied is more representative of the general population than that of most other studies, and the data on prevalence of chronic liver disease as well as of risk factors for liver disease were collected according to a well defined protocol. In the present work, we report on the prevalence and genotype composition of HCV infection in the general population in relation to sex, age, daily alcohol intake, and risk factors for exposure to $\mathrm{HCV}$ infection. In addition, a three year prospective study was performed to examine the natural history of $\mathrm{HCV}$ infection and the influence of cofacors on the natural history of cirrhosis and its evolution to HCC.
Compared with previous reports, this study showed a higher prevalence of anti-HCV antibodies. Prevalence of anti-HCV positivity in our population was $3.2 \%$, three times that reported in several series studying blood donors, ${ }^{33-35}$ but lower than that recently reported in a large random US population $(7 \%) .^{36}$ Recent data ${ }^{37-39}$ from Central and Southern Italy also indicate that HCV infection is more frequent ( 8.4 and $12.6 \%$ respectively) than in our study. It is clear that prevalence of anti-HCV positivity is very sensitive to population and geography. Prevalence of anti-HCV positivity was higher in women than in men, and in older ( $>45$ years old) than younger people, in keeping with other studies. ${ }^{14-16} 36-40$

On the basis of RIBA and PCR HCV RNA assays, our results showed that only $72 \%$ of the anti-HCV positive patients were HCV RNA positive, and that there was a $12 \%$ false positive rate for anti-HCV assays. Therefore, of the $28 \%$ of the subjects who were HCV RNA negative, $12 \%$ probably never had the disease, and $16 \%$ had the disease but probably cleared the virus. This figure is similar to the $9-10 \%$ false positive anti-HCV assays previously reported, and it is identical with the $16 \%$ of RIBA positive healthy blood donors who are HCV RNA negative reported in the United States. ${ }^{36}$

Distribution of HCV genotypes was different from that reported in several recent studies. For example, prevalence of genotype $1 \mathrm{~b}$ was less $(42 \%$, or $51 \%$ if including multiple genotypes) than that in other reports from the same geographic area (65-70\%). ${ }^{9}$ Among patients infected with HCV, genotype distribution shows wide geographic differences. The prevalence of genotype $1 \mathrm{~b}$ is high in Japan $(78 \%),{ }^{41}$ intermediate in Italy $(68 \%),{ }^{11}{ }^{42}$ and low in the United States (21\%). ${ }^{17}$ The risk factors for transmission of $\mathrm{HCV}$ were similar to those reported by others, ${ }^{43-45}$ with the exception of animal bites (mainly dog bites) which has not been reported before. We have no explanation of this finding, which must in any case be regarded with caution, because of other confounding factors such as the social condition of the subject (in our cohort most of the people that own a dog are farmers).

We also found that $35 \%$ of the HCV RNA positive subjects had consistently normal ALT and GGT values during the three years of follow up, a figure similar to other series. ${ }^{10}{ }^{16} \mathrm{As}$ other authors recently reported the presence of mild to severe chronic hepatitis in HCV RNA positive patients with normal ALT, ${ }^{46}{ }^{47}$ we may have missed some cases of active hepatitis when we set biopsy criteria at ALT more than 1.5 times normal. Therefore, in order to understand which factors among age, sex, alcohol intake, and HCV genotypes in our cohort are important in the evolution of chronic liver disease, we selected histologically proven cirrhosis and/or HCC as the final outcome in the multivariate analysis. In line with other series, ${ }^{11} 1440$ our data indicate that, independently of HCV genotype, male sex and alcohol abuse were closely associated with the presence of both cirrhosis and HCC. As in our cohort we cannot 
establish the exact time when the $\mathrm{HCV}$ infection was contracted, we were not able to correct our data for the duration of infection. However, multivariate analysis after correction for age, sex, and alcohol intake indicated that the relative risk of having cirrhosis and/or HCC is significantly more closely associated with the presence of $\mathrm{HCV}$ genotype $1 \mathrm{~b}(\mathrm{OR}=31)$ than the presence of other genotypes $(\mathrm{OR}=11.2$, $\mathrm{p}<0.0001)$. As the mean age of the patients infected by different HCV genotypes is similar and the design of our study - that is, population based-avoids the bias of a patient oriented selection, these data suggest that the greater severity of HCV type $1 \mathrm{~b}$ chronic liver disease is not only due to an age "cohort effect". They also indicate that the risk of progression to cirrhosis depends primarily on $\mathrm{HCV}$ infection, mainly type $1 \mathrm{~b}$ infection, rather than the age of the patient at the time of infection. Our findings are in conflict with those of other studies, which showed no impact of HCV genotype on the severity of chronic liver disease,${ }^{14}{ }^{15}$ but are in line with other reports, ${ }^{101141}$ including a recent one from the same geographic area, ${ }^{16}$ which showed a high prevalence of genotype $1 \mathrm{~b}$ infection in patients with cirrhosis and/or HCC. This is probably due to the fact that important cofactors in the progression of chronic liver disease, such as excessive alcohol intake, have not been taken into account by other authors. In addition, earlier studies are mainly based on selected populations, while the latter concordant studies $^{1011} 16$ are all either case-control or cross-sectional studies of a well defined homogeneous population.

In conclusion, this cohort study provides reliable information on $\mathrm{HCV}$ genotype and chronic liver disease in an open population. From these data we can conclude that: (a) the prevalence of HCV related infection is higher than reported in selected series (in women more than in men, and age dependent); $(b)$ genotype $1 \mathrm{~b}$ is the most prevalent genotype, but it is less widespread than previously reported in selected series of patients affected by $\mathrm{HCV}$ induced chronic liver disease; $(c)$ main risk factors for HCV infection in the Dionysos open population are similar to those found in selected series, with the exception of animal bites; (d) more than $50 \%$ of the HCV RNA positive subjects showed no clinical and biochemical signs of liver damage or had only a slight increase in either ALT or GGT during the three years of follow up; (e) the association between $\mathrm{HCV}$ infection, especially genotype $1 \mathrm{~b}$ infection, and alcohol abuse dramatically enhances the liver damage and the progression of cirrhosis to HCC; $(f)$ independently of age, sex, and alcohol intake, HCV infection, particularly with genotype $1 \mathrm{~b}$, is the major risk factor associated with the presence of cirrhosis and/or HCC in the general population, at least of Northern Italy. However, further studies providing prospective data on the real duration and natural history of $\mathrm{HCV}$ infection are necessary to confirm this latter finding.
We thank Gerry Morgan Hardison, VAMC, San Diego, California, USA, for critical reading of the manuscript, and Dr Stefano Viaggi, Link-Italia, Modena, Italy for the elaboration of the data. This study was supported by grants from Fondo Studi Fegato, Telethon (grant no E396). This paper was presented to the 31st EASL Annual Meeting, Geneva, Switzerland, 25-29 August 1996 , and published in abstract form ( $F$ Hepatol 1996;25:815).

1 Bukh J, Miller RH, Purcell RH. Genetic heterogeneity of hepatitis C virus: quasispecies and genotypes. Semin Liver Dis 1995;15:41-63.

2 Simmonds P. Variability of hepatitis C virus. Hepatology 1995;21:570-83.

3 Stuyver L, Van Arnhem W, Wyseur A, et al. Classification of hepatitis C virus based on phylogenetic analysis of the envelope 1 and nonstructural $5 \mathrm{~B}$ regions and identification of five additional subtypes. Proc Natl Acad Sci USA 1994;91:10134-8.

4 Takada A, Tsusumi M, Okanoue T, et al. Distribution of different subtypes of hepatitis $C$ virus in Japan and the effects of interferon: a nationwide survey. $\mathcal{F}$ Gastroenterol Hepatol 1996;11:201-7.

5 Takada N, Takase S, Enomoto N, et al. Clinical background of the patients having different types of hepatitis $\mathrm{C}$ virus genome. F Hepatol 1992;14:35-40.

6 Alter MJ, Margolis HS, Krawczynski K, et al. The natural history of community-acquired hepatitis $\mathrm{C}$ in the United States. N Engl F Med 1992;327:1899-905.

7 Nousbaum JB, Pol S, Nalpas B, et al. Hepatitis C virus type $1 b$ (II) infection in France and Italy. Collaborative study. Ann Intern Med 1995;122:161-8.

Ann Intern Med 1995;122:161-8.
8 Pozzato G, Kanedo S, Moretti M, et al. Different genotypes Pozzato G, Kanedo S, Moretti M, et al. Different genotypes of hepatitis C virus are associated with different seve
chronic liver disease. $\mathcal{F}$ Med Virol 1994;43:291-6.

9 Crovatto M, Modolo ML, Franzin F, et al. Direct evidence for a more aggressive liver disease in genotype II of hepatitis C virus. Ital $\mathcal{F}$ Gastroenterol 1993;25:453-4.

10 Silini E, Bono F, Cividini A, et al. Differential distribution of hepatitis $C$ virus genotypes in patients with and without liver function abnormalities. Hepatology 1995;21:285-90.

11 Silini E, Bottelli R, Asti M, et al. Hepatitis C virus genotypes and risk of hepatocellular carcinoma in cirrhosis: a case-control study. Gastroenterology 1996;111:199-205.

12 Prati D, Capelli C, Zanella A, et al. Influence of different hepatitis $C$ virus genotypes on the course of asymptomatic hepatitis C infection. Gastroenterology 1996;110:178-83.

13 Berg T, Hopf U, Stark K, et al. Distribution of hepatitis C virus genotypes in German patients with chronic hepatitis C: correlation with clinical and virological paramenters. $\mathcal{F}$ Hepatol 1997;26:484-91.

14 Benvegnù L, Pontisso $\mathrm{P}$, Cavalletto $\mathrm{D}$, et al. Lack of correlation between hepatitis $C$ virus genotypes and clinical course of hepatitis C virus-related cirrhosis. Hepatology 1997;25:211-15.

15 Mangia A, Cascavilla I, Lezzi G, et al. HCV genotypes in patient with liver disease of different stages and severity. $\mathcal{F}$ Hepatol 1997;26:1173-8.

16 Bruno S, Silini E, Crosignani A, et al. Hepatitis C virus genotypes and risk of hepatocellular carcinoma in cirrhosis: a prospective study. Hepatology 1997;25:754-8.

17 Zein NN, Rakela J, Krawitt EL, et al. Hepatitis C virus genotypes in United States: epidemiology, pathogenicity, and response to interferon therapy. Collaborative Study and response to interferon therapy. Colla

18 Bellentani S, Tiribelli C, Saccoccio G, et al. Prevalence of chronic liver disease in the general population of Northern chronic liver disease in the general population of North

19 Bellentani S, Saccoccio G, Costa G, et al. Drinking habits as cofactors of risk for alcohol-induced liver damage. Gut 997;41:845-50

20 Block G, Hartmann AM, Dresser CM, et al. A databased approach to diet questionnaire design and testing. Am $\mathcal{F}$ Epidemiol 1986;124:453-69.

21 Reshef A, Epstein LM. Reliability of a dietary questionnaire. Am $\mathcal{F}$ Clin Nutr 1972;25:91-5.

22 Cubean J, Pequignot G. La tecnique du questionnaire alimentaire quantitatif utilise par la section nutrition de l'I.N.S.E.R.M. Rev Epidemiol Med Soc Sante Publique 1980; 28:367-72.

23 Riboli E, Pequignot G, Repetto F, et al. A comparative study of smoking, drinking and dietary habits in population sample in France, Italy, Spain and Switzerland. I. Study design and dietary habits. Rev Epidemiol Med Soc Sante Publique 1988;36:151-65.

24 Paton A, Saunders JB. ABC of alcohol. BMF 1981;283: 1248-50.

25 Midanik L. The validity of self-reported alcohol consumption and alcohol problems: a literature review. British fournal of Addiction 1982;77:357-82.

26 Okamoto H, Sugiyama Y, Okada S, et al. Typing hepatitis C virus by polymerase chain reaction with type-specific primers: application to clinical surveys and tracing infections sources. F Gen Virol 1992;73:673-9.

27 Okamoto $\mathrm{H}$, Tokita $\mathrm{H}$, Sakamoto $\mathrm{M}$, et al. Characterization of the genomic sequence of type $\mathrm{V}$ (or $3 \mathrm{a}$ ) hepatitis $\mathrm{C}$ virus isolates and PCR primers for specific detection. 7 Gen Virol 1993;74:2385-90.

28 Simmonds P, Alberti A, Alter HJ, et al. A proposed system for the nomenclature of hepatits $C$ viral genotypes. for the nomenclature of
Hepatology 1994;19:1321-4.

29 Cammarota G, Maggi F, Vatteroni ML, et al. Partial nucleotide sequencing of six subtype $2 \mathrm{c}$ hepatitis $\mathrm{C}$ viruses otide sequencing of six subtype 2c hepatitis C
detected in Italy. $\mathcal{F}$ Clin Microbiol 1995;33:2781-4. 
30 Meier P, Beach M. Biostatistics for the clinician. In: Chalmers TC, ed. Data analysis for clinical medicine. Rome: Interers TC, ed. Data analysis for clinical m
national University Press, 1988:7-29.

31 Fleiss JL. Statistical methods for rates and proportions. New York: Wiley and Sons, 1981:83-99.

32 Hosmer DW Jr, Lemeshow S. Applied logistic regression. New York: John Wiley, 1989

33 Conry-Cantilena C, VanRaden M, Gibble J, et al. Routes of infection, viremia, and liver disease in blood donors found to have hepatitis C virus infection. N Engl f Med 1996;334 1691-6.

34 Sirchia G, Almini D, Bellobuono A. Prevalence of hepatitis C virus antibodies in italian blood donors. Vox Sang 1990; 59:26-9.

35 Stevens CE, Taylor PE, Pindyck J, et al. Epidemiology of hepatitis $\mathrm{C}$ virus: a preliminary study in volunteer blood donors. ҰAMA 1990;263:49-53.

36 Kaur S, Rybicki L, Bacon BR, et al. Performance characteristics and results of a large-scale screening program for viral istics and results of a large-scale screening program for viral hepatitis B and C: results of the National Hepatitis Screening Survey. Hepatology 1996;24:979-86.

37 Sagnelli E, Stroffolini T, Caporaso N, et al. Hepatitis C virus infection in Italy: a multicentric seroepidemiological study. Ital f Gastroenterol 1991;23:555-8.

38 Stroffolini T, Menchinelli M, Taliani G, et al. High prevalence of hepatitis $\mathrm{C}$ virus infection in a small central Italian town: lack of evidence of parenteral exposure. Ital $\mathcal{F}$ Gastroenterol 1995;27:235-8.

39 Guadagnino V, Stroffolini T, Rapicetta M, et al. Prevalence, risk factors and molecular epidemiology of hepatitis $\mathrm{C}$ virus infection in the general population. A communitybased survey in a Southern Italian town [abstract]. 7 Hepatol 1997;26(suppl):222.

40 De Bac C, Stroffolini T, Gaeta GB, et al. Pathogenic factors in cirrhosis with and without hepatocellular carcinoma: multicenter italian study. Hepatology 1994;20:1225-30.

41 Kobayashi M, Kumada H, Chayama K, et al. Prevalence of HCV genotype among patients with chronic liver disease in the Tokyo metropolitan area. 7 Gastroenterol 1994;29.583 7.

42 Pontisso P, Ruvoletto MG, Nicoletti M, et al. Distribution of three major hepatitis $\mathrm{C}$ virus genotypes in Italy. A
multicenter study of 495 patients with chronic hepatitis. $\mathcal{F}$ multicenter study of 495 pati

43 Zeuzem S, Teuber G, Lee JH, et al. Risk factors for the transmission of hepatitis C. F Hepatol 1996;24(suppl 2):310.

44 Watson JP, Brind AM, Chapman CE, et al. Hepatitis C virus: epidemiology and genotypes in the north-east of England. Gut 1996;38:269-76.

45 Dubois F, Desenclos JC, Mariotte N, et al. Hepatitis C in a French population-based survey, 1994: seroprevalence, frequency of viremia, genotype distribution, and risk factors. quency of viremia, genotype
Hepatology 1997;25:1490-6.

46 Puoti C, Magrini A, Filippi T, et al. Do symptomless HCV carriers spread infection to their relatives? Lancet 1995;346: 843.

47 Stati T, Magrini A, Montagnese F, et al. Liver histology in HCV-RNA carriers with persistently normal serum ALT levels. F Hepatol 1997;26(suppl 1):73. 